\title{
BEHAVIOR OF BROADCAST IONOSPHERIC-DELAY MODELS FROM GPS, BEIDOU, AND GALILEO SYSTEMS
}

\author{
Ashraf Farah \\ Associate Professor, College of Engineering, Aswan University, Aswan, Egypt. \\ Associate Professor, College of Engineering, King Saud University, Riyadh, KSA. \\ ashraf_farah@aswu.edu.eg
}

\begin{abstract}
The GNSS observations suffer from different types of errors that could affect the achieved positioning accuracy based on the receiver type used. Single-frequency receivers are widely used worldwide because of its low cost. The ionospheric delay considers the most challenging error for single-frequency GNSS observations. All satellite navigation systems, except GLONASS, are advising their users to correct for the ionospheric delay using a certain model. Those models' coefficients are sent to users in the system's navigation message. These models are different in their accuracy and behavior based on its foundation theory as well as the updating rate of their coefficients. The GPS uses Klobuchar model for mitigating the ionospheric delay. BeiDou system (BDS-2) adopts a slightly modified Klobuchar model that resembles GPS ICA (Ionospheric Correction Algorithm) with eight correction parameters but is formulated in a geographic coordinate system with different coefficients in origin and updating rate. Galileo system uses a different model (NeQuick model). This article investigates the behavior of the three models in correcting the ionospheric delay for three stations at different latitudes during 3 months of different states of ionospheric activity, comparing with International GNSS Service-Global Ionospheric Maps (IGS-GIMs). It is advised from this research's outputs to use the GPS model for mitigating the ionospheric delay in low-latitude regions during the state of low-and medium-activity ionosphere. It is advised to use the BeiDou model for mitigating the ionospheric delay in mid-latitude regions during different states of ionospheric activity. It is advised to use the Galileo model for mitigating the ionospheric delay in high-latitude regions during different states of ionospheric activity. Also, the Galileo model is recommended for mitigating the ionospheric delay for low-latitude regions during the state of high-activity ionosphere.
\end{abstract}

Keywords: Ionospheric delay, Broadcast model, GPS, Galileo, BeiDou

\section{INTRODUCTION}

The quality of GNSS positioning depends on proper mitigations of errors that affect the quality of its observations. Signals of the GNSS face varying amount of delays when passing through different layers of atmosphere such as troposphere and ionosphere. The delay caused by the ionosphere layer considers one of the greatest sources of error faced by GNSS observations (Kunches and Klobuchar, 2001). The ionospheric delay can be up to tens of meters in magnitude and severely impact various operations for satellite navigation systems (Hernández-Pajares et al., 2011). 
Users of high-cost dual-frequency receivers could remove the first order of the ionospheric delay by applying ionosphere-free (IF) combination through combining two frequency simultaneous measurements (Hofmann-Wellenhof, 2008). Users of low-cost single-frequency receivers must apply a certain model to correct for the ionospheric delay. Different types of models varying in input parameters, computation demand, and accuracy are developed. There are computationally demanding models, such as Bent model (Newby and Langely, 1992) and International Reference Ionosphere (IRI)-2000 model (Bilitza, 2001), that require regular updating of large amount of solar flux and Zurich sunspot numbers input data. Also there are computationally simple theoretical models, such as Klobuchar model (Klobuchar, 1987) and NeQuick model (European Commission, 2016; Rovira-Garcia et al., 2016) that do not require regular updating of ionosphere-related parameters. Those models are favorable for GNSS operations as their limited-number coefficients could be sent to users in navigation message of each system. The American GPS system advices its users to correct the ionospheric delay using the Klobuchar model and sent the model's eight coefficients through its navigation message. Klobuchar model's coefficients that do not update regularly are selected based on the day of year (DOY) and the average solar flux values of the previous 5 days (Klobuchar, 1987). The Chinese BeiDou system (BDS-2) uses a slightly modified Klobuchar model for correcting the ionospheric delay in geographic coordinate system. The broadcast coefficients of the BeiDou-Klobuchar model are calculated from the regional Chinese monitoring stations and updated every 2 hours (Wu et al., 2013; Wang et al., 2018). The Klobuchar model is adopted for ionospheric delay correction by other satellite navigation systems such as the Indian Regional Navigation Satellite System (IRNSS) and Japan's Quasi-Zenith Satellite System (QZSS) (Ningbo et al., 2018). Galileo system adopted the NeQuick model for ionospheric delay correction. Galileo navigation message contains three daily updated coefficients to users to calculate the effective ionization level (Az) parameter used by the NeQuick model (Prieto-Cerdeira et al., 2014; European Commission, 2016).

This research presents the behavior of the three models used for ionospheric delay correction by three GNSS systems: GPS, BeiDou (BDS-2), and Galileo. The tested models are the Klobuchar model using the GPS broadcast coefficients (GPS model), the Klobuchar model using BeiDou-coefficients (BDS-2) (BeiDou model), and the NeQuick model. The ionospheric coefficients for tested models used in this research were derived from IGS organization (IGS, 2019a) The ionospheric range delay correction offered by the three models has been examined by the International GNSS Service-Global Ionospheric Maps (IGS-GIMs) (IGS, 2019b) for three stations at different latitudes (Table 1) to reflect models' behavior in different geographic regions. The study covers three different (ionospheric activity) months (Table 2) that each of them reflects a different state of activity of the ionosphere layer based on the solar activity (SIDC, 2019).

Table 1. The geographical positions of the tested stations.

\begin{tabular}{|l|l|l|l|}
\hline Station ID & $\begin{array}{l}\text { Latitude } \\
\text { (degree) }\end{array}$ & $\begin{array}{l}\text { Longitude } \\
\text { (degree) }\end{array}$ & $\begin{array}{l}\text { Height } \\
\text { (m) }\end{array}$ \\
\hline Aswan & $24.088 \mathrm{~N}$ & $32.899 \mathrm{E}$ & 79.000 \\
\hline Sofia & $42.700 \mathrm{~N}$ & $23.333 \mathrm{E}$ & 549.000 \\
\hline Helsinki & $60.192 \mathrm{~N}$ & $24.946 \mathrm{E}$ & 17.000 \\
\hline
\end{tabular}


Table 2. The tested monthes, activity states, average monthly Sun Spot number, average monthly 10.7-cm solar radio flux (F10.7), and average monthly planetary K-index (Kp) (SIDC, 2019).

\begin{tabular}{|l|l|l|l|}
\hline $\begin{array}{l}\text { Ionospheric } \\
\text { Activity state }\end{array}$ & Low & Medium & High \\
\hline Tested month & August 2019 & April 2017 & May 2016 \\
\hline $\begin{array}{l}\text { Monthly average } \\
\text { Sun Spot number }\end{array}$ & 0.74 & 32.30 & 51.50 \\
\hline F10.7 & 67.05 & 80.91 & 93.39 \\
\hline Kp-index & 7.09 & 12.50 & 14.71 \\
\hline
\end{tabular}

\section{GPS-KLOBUCHAR MODEL}

The Klobuchar model is a simple broadcast ionospheric model built on a simple cosine representation of the ionospheric delay (Klobuchar, 1987). The model has a fixed-phase zero at 14.00 hours local time and a constant night time offset of $5 \mathrm{~ns}$. The period and amplitude of the ionospheric delay are represented as third-degree polynomials in local time and geomagnetic latitude. The eight time-varying coefficients of the model are broadcast in the GPS navigation message. GPS master control station selects those coefficients from 370 possible sets of constants based on 2 parameters: DOY and an average solar of 10.7-cm flux value.

Given the user approximate geodetic latitude $\left(\emptyset_{\mathrm{u}}\right)$, longitude $\left(\lambda_{u}\right)$, elevation angle in semicircles $(E)$, azimuth $(A)$ of the observed satellite, and the coefficients $\left(\alpha_{n}\right)$ and $\left(\beta_{n}\right)$ broadcasted in the GPS satellite navigation message (Klobuchar, 1987), the earth-centered angle $(\psi)$, the latitude of the ionospheric pierce point (IPP) $\left(\varnothing_{I}\right)$, and longitude of the IPP $\left(\lambda_{I}\right)$ can be calculated using equations (1), (2), and (3), respectively;

$$
\begin{aligned}
& \psi=\frac{0.0137}{E+0.11}-0.022 \quad \text { (semicircles) } \\
& \phi_{I}=\phi_{u}+\psi \cos A \quad \text { (semicircles) } \\
& \text { If } \Phi_{I}>+0.416 \quad \text { the } \Phi_{I}=+0.416 . \\
& \text { If } \Phi_{I}<-0.416 \quad \text { the } \Phi_{I}=-0.416 . \\
& \lambda_{I}=\lambda_{u}+\frac{\psi \sin A}{\cos \phi_{I}} \quad \text { (semicircles) }
\end{aligned}
$$

The geomagnetic latitude of the IPP $\left(\emptyset_{m}\right)$ and the local time at the IPP $(t)$ can be estimated using equations (4) and (5), respectively;

$$
\begin{gathered}
\phi_{m}=\phi_{I}+0.064 \cos \left(\lambda_{I}-1.617\right) \quad \text { (semicircles) } \\
t=43200 \lambda_{I}+t_{G P S}(\text { seconds) }
\end{gathered}
$$

where $\leq t<86400$.

Therefore, if $t \geq 86400$, subtract 86400 , and if $t<0$, add 86400 . 
The amplitude of the ionospheric delay $\left(A_{I}\right)$, the period of ionospheric delay $\left(P_{I}\right)$, and the phase of the ionospheric delay $\left(X_{I}\right)$ can be estimated from equations (6), (7), and (8), respectively;

$$
\begin{aligned}
& A_{I}=\sum_{n=0}^{3} \alpha_{n} \phi_{m}^{n} \quad \text { (seconds) } \\
& \text { if } A_{I}<0 \text {, then } A_{I}=0 . \\
& P_{I}=\sum_{n=0}^{3} \beta_{n} \phi_{m}^{n} \quad \text { (seconds) }
\end{aligned}
$$

if $P_{I}<72000$, then $P_{I}=72000$.

$$
X_{I}=\frac{2 \pi(t-50400)}{P_{I}} \quad \text { (radians) }
$$

Finally, the slant factor $(F)$ and the ionospheric time delay (ILIGPS) can be calculated using equations (9) and (10), respectively;

$$
\begin{aligned}
& F=1.0+16.0(0.53-E)^{3} \\
& I_{\text {LLaPs }}= \begin{cases}{\left[5 \cdot 10^{-9}+\sum_{n=0}^{3} \alpha_{n} \phi_{m}^{n} \cdot\left(1-\frac{x_{I}^{2}}{2}+\frac{x_{f}}{24}\right)\right] \cdot F} & ;\left|X_{l}\right| \leq 1.57 \\
5 \cdot 10^{-9} \cdot F & ;\left|X_{l}\right| \geq 1.57\end{cases}
\end{aligned}
$$

The delay for any GNSS signal $\left(I_{f}\right)$ transmitted on frequency $(f)$ is given by the following equation:

$$
I_{f}=\left(\frac{f_{L 1_{G P S}}}{f}\right)^{2} I_{L 1_{G P S}}
$$

\section{BEIDOU-KLOBUCHAR MODEL}

The BeiDou system (BDS-2) uses eight parameters-Klobuchar model for correcting the ionospheric delay for single-frequency users. According to Zhao et al. (2014), Prasad and Sarma (2004), and Sharma and Galav (2011), the zenith ionospheric delay can be calculated as follows:

$I_{z}(t)= \begin{cases}5 \times 10^{-9}+A_{2} \cos \left[\frac{2 \pi(t-50,400)}{A_{4}}\right], & |t-50,400|<A_{4} / 4 \\ 5 \times 10^{-9} & |t-50,400| \geq A_{4} / 4\end{cases}$ 
where

$\mathrm{I}_{\mathrm{z}} \quad$ is the zenith ionospheric delay for signal frequency B1 (seconds),

$\mathrm{t} \quad$ is the time of intersection between the line of receiver to satellite and the ionosphere (in the range of $0-86400$ ) in seconds,

$\mathrm{A}_{2} \quad$ is the amplitude of the cosine curve on the day calculated by $\alpha_{\mathrm{n}}$ coefficients.

$$
A_{2}=\left\{\begin{array}{l}
\sum_{n=0}^{3} \alpha_{n}\left|\phi_{M}\right|^{n} A_{2}>0 \\
0 \quad A_{2}<0
\end{array}\right.
$$

A4 is the period of a cosine curve calculated using the coefficients $\beta_{\mathrm{n}}$ (seconds).

$$
A_{4}= \begin{cases}1,72,800 & A_{4} \geq 1,72,800 \\ \sum_{n=0}^{3} \beta_{n}\left|\phi_{M}\right|^{n} & 1,72,800>A_{4} \geq 72,000 \\ 7,200 & A_{4}<72,000\end{cases}
$$

where $\phi_{M}$ is the latitude of puncture point (radians). $\phi_{M}$ and $\lambda_{M}$ can be calculated as follows:

$$
\begin{aligned}
& \phi_{M}=\arcsin \left(\sin \phi_{u} \cos \psi+\cos \phi_{u} \sin \psi \cos A\right) \\
& \lambda_{M}=\lambda_{u}+\arcsin \left(\frac{\sin \psi \sin A}{\cos \phi_{M}}\right)
\end{aligned}
$$

where

$$
\begin{array}{ll}
\phi_{u} & \text { is the user geographic latitude (radians), } \\
\lambda_{u} & \text { is the user geographic longitude (radians), } \\
A & \text { is satellite azimuth (radians), } \\
\psi & \text { is geocentric opening angle between user and puncture (radians), which is calculated }
\end{array}
$$
as follow:

$$
\psi=\frac{\pi}{2}-E-\arcsin \left(\frac{R}{R+h} \cos E\right)
$$

where

$R \quad$ is the radius of the Earth $(6,378 \mathrm{~km})$,

$E \quad$ is satellite elevation angle (radians),

$h \quad$ is the height of the ionosphere monolayer $(375) \mathrm{km}$.

$I_{z}(t)$ can be converted to $I_{B 1 I}(t)$ through $I_{B 1 I}(t)=\frac{1}{\sqrt{1-\left(\frac{R}{R+h} \cos E\right)}} \cdot I_{z}(t)$.

\section{GALILEO-NEQUICK MODEL}

The NeQuick model is a quick-run ionospheric electron density model particularly designed for trans-ionospheric propagation applications, developed by the Abdus Salam International Center of Theoretical Physics (ICTP) and the University of Graz (Di Giovanni and Radicella, 1990). The original NeQuick1 was updated to NeQuick2 by modification of both the bottomside and topside formulations (Nava et al., 2008), which constitutes the baseline of the Galileo-NeQuick model (European Commission, 2016). The Galileo model is designed to correct $70 \%$ of the ionospheric propagation error (Rovira-Garcia et al., 2014). The model is driven by effective ionization level (Az), which can be computed using three daily updated 
ionospheric correction coefficients $(a 0, a 1$, and $a 2)$ that are transmitted in Galileo navigation message.

$$
A z(\mu)=a_{0}+a_{1} \mu+a_{2} \mu^{2}
$$

where $\mu$ is a modified dip (MODIP) of the user location expressed in degree.

$$
\tan \mu=\frac{I}{\sqrt{\cos \phi}}
$$

in which $I$ is the magnetic inclination at $300-\mathrm{km}$ altitude and $\phi$ is the geographic latitude of the user location.

\section{BEHAVIOR TEST STUDY}

This study compares the behavior of three broadcast ionospheric models from three systems (GPS, BeiDou, and Galileo) for zenith ionospheric delay estimation. The models' estimations for (GPS-L1 signal; $1575.42 \mathrm{MHz}$ ) are compared with the IGS-GIMs. The study is applied on three stations at different latitudes (Table 1) to reflect different geographical regions (low, mid, and high). The study covers three different months (Table 2). Each month reflects a different state of activity of the ionosphere layer (quiet, medium, and active) based on the Sun Spot number (SSN), F10.7, and Kp-index values (Table 2).

\subsection{Low-latitude geographic region}

The zenith ionospheric delay estimations presented by the GPS, BeiDou, and Galileo models with the IGS-GIMs are presented in Figures 1-3 for low-latitude station (Aswan). The zenith ionospheric delay differences for the three models with respect to the IGS-GIMs are presented in Figures 4-6.

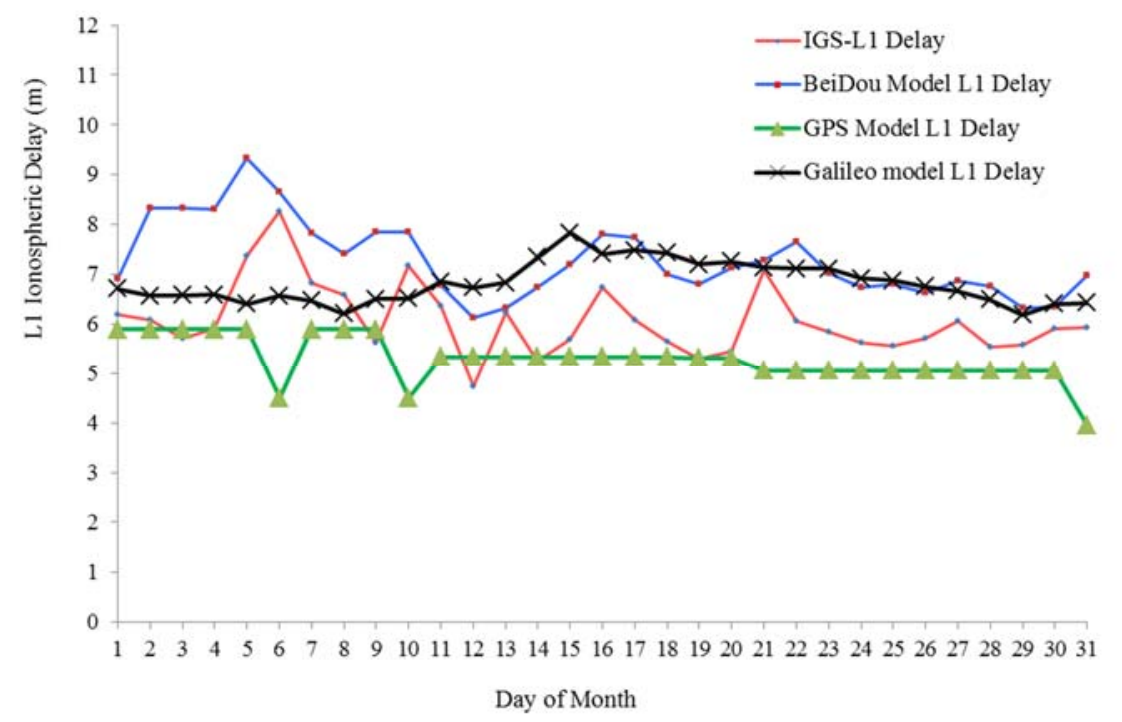

Figure 1. L1 Ionospheric delay using the GPS model, BeiDou model, Galileo model, and IGS-GIMs for Aswan station during May 2016. 


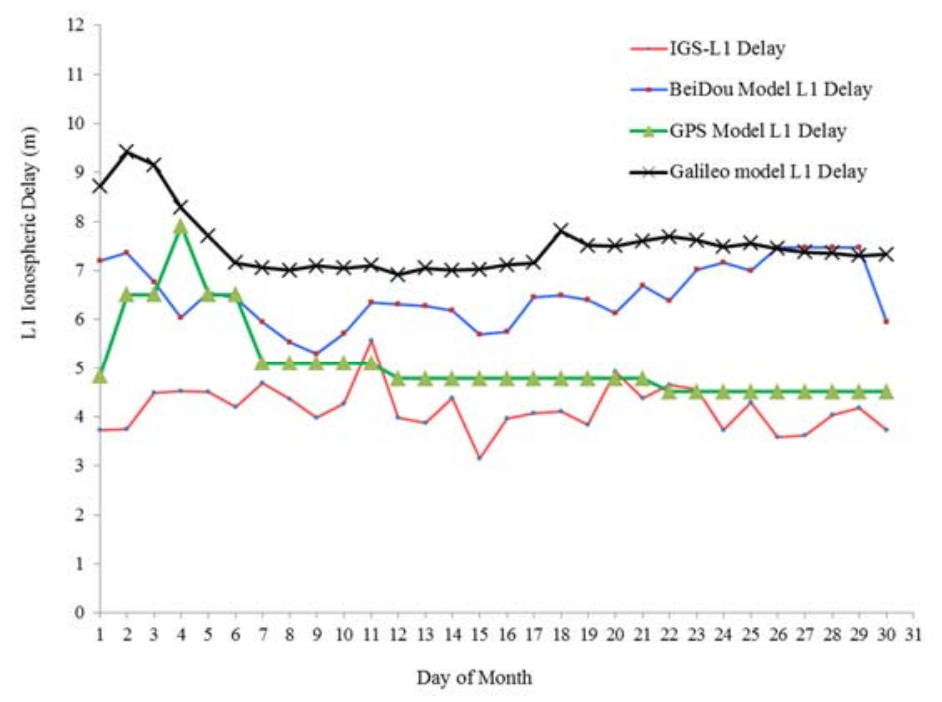

Figure 2. L1 ionospheric delay using the GPS model, BeiDou model, Galileo model, and IGS-GIMs for Aswan station during April 2017.

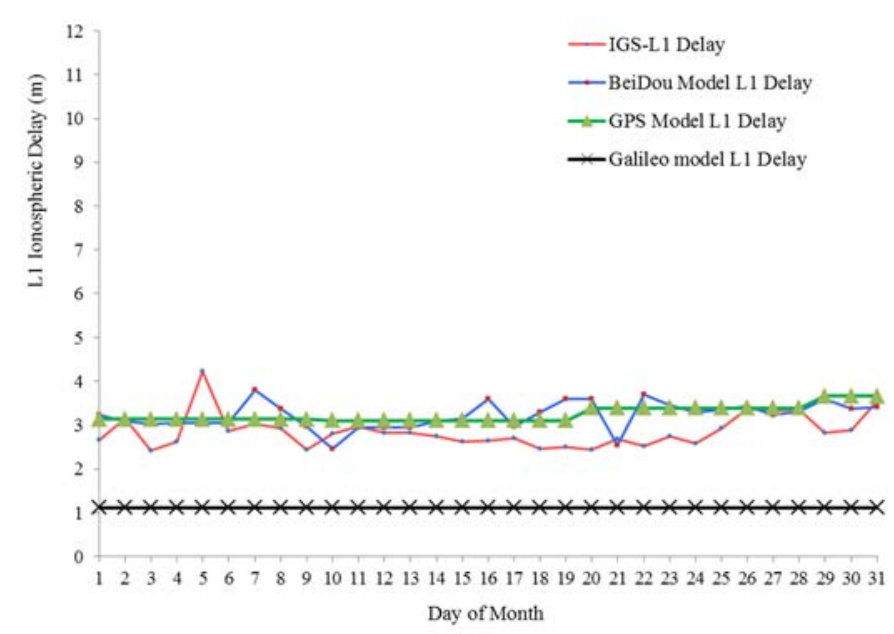

Figure 3. L1 Ionospheric delay using the GPS model, BeiDou model, Galileo model, and IGS-GIMs for Aswan station during August 2019.

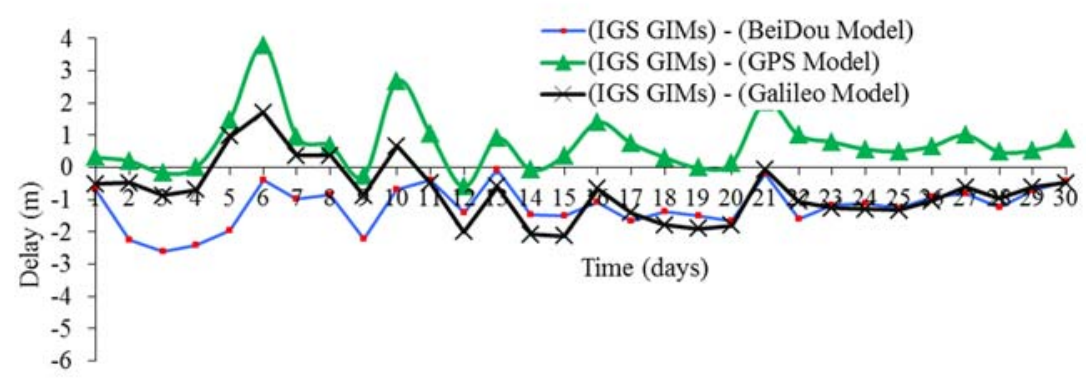

Figure 4. L1 range delay difference for Aswan station during May 2016. 


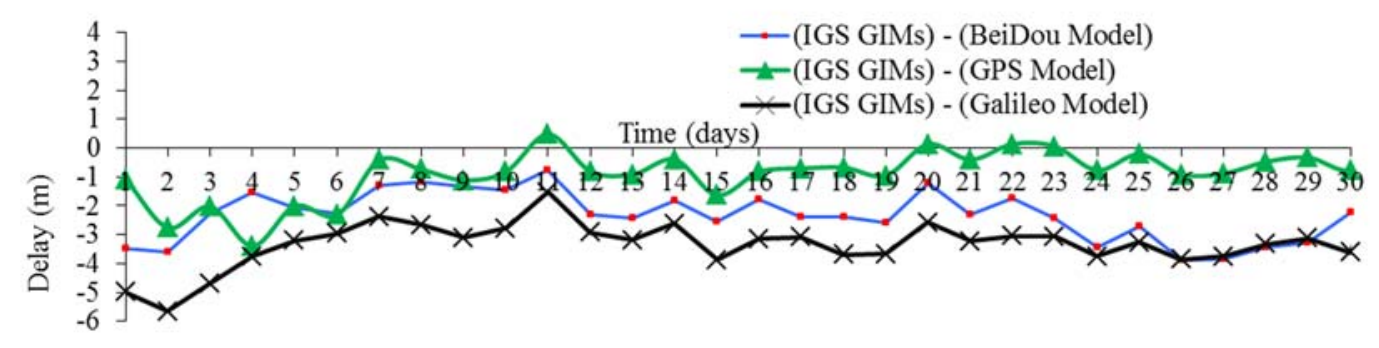

Figure 5. L1 range delay differences for Aswan station during April 2017.

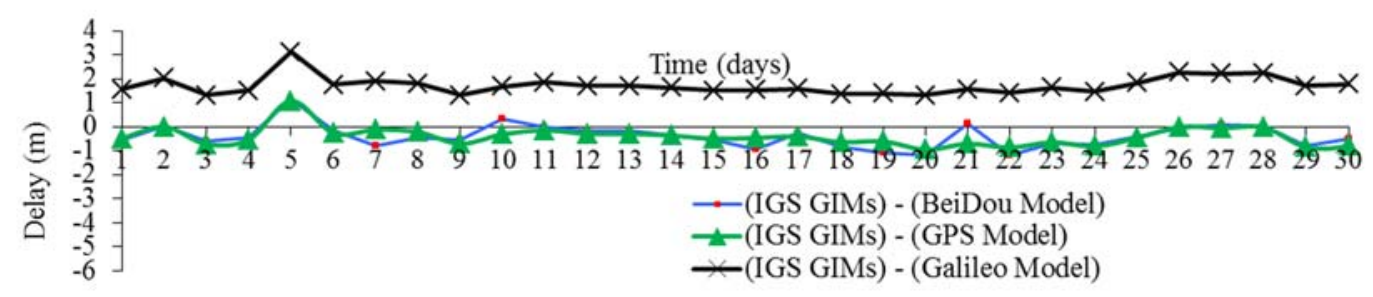

Figure 6. L1 range delay difference for Aswan station during August 2019.

\subsection{Mid-latitude geographic region}

The zenith ionospheric delay estimations presented by the GPS, BeiDou, and Galileo models with the IGS-GIMs are presented in Figures 7-9 for mid-latitude station (Sofia). The zenith ionospheric delay differences for the three models with respect to the IGS-GIMs are presented in Figures 10-12.

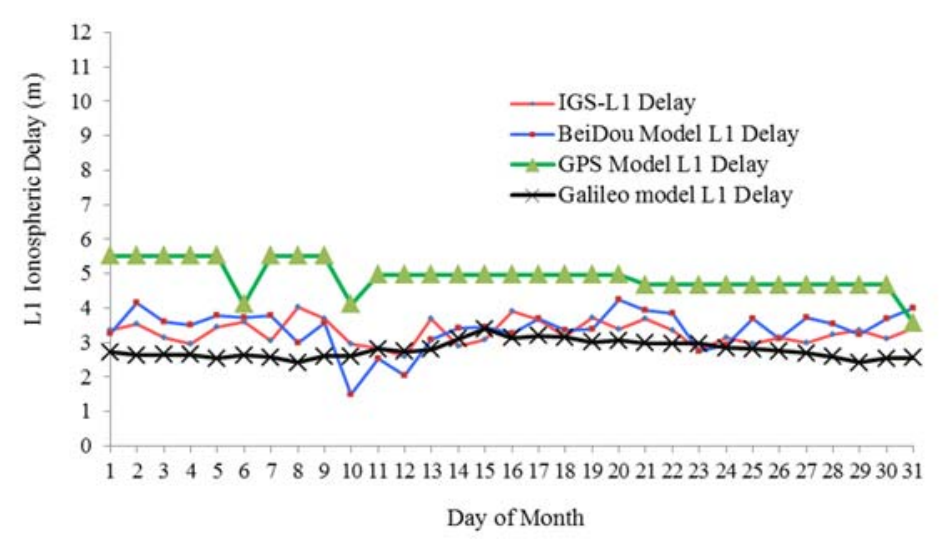

Figure 7. L1 ionospheric delay using the GPS model, BeiDou model, Galileo model, and IGS-GIMs for Sofia station during May 2016. 


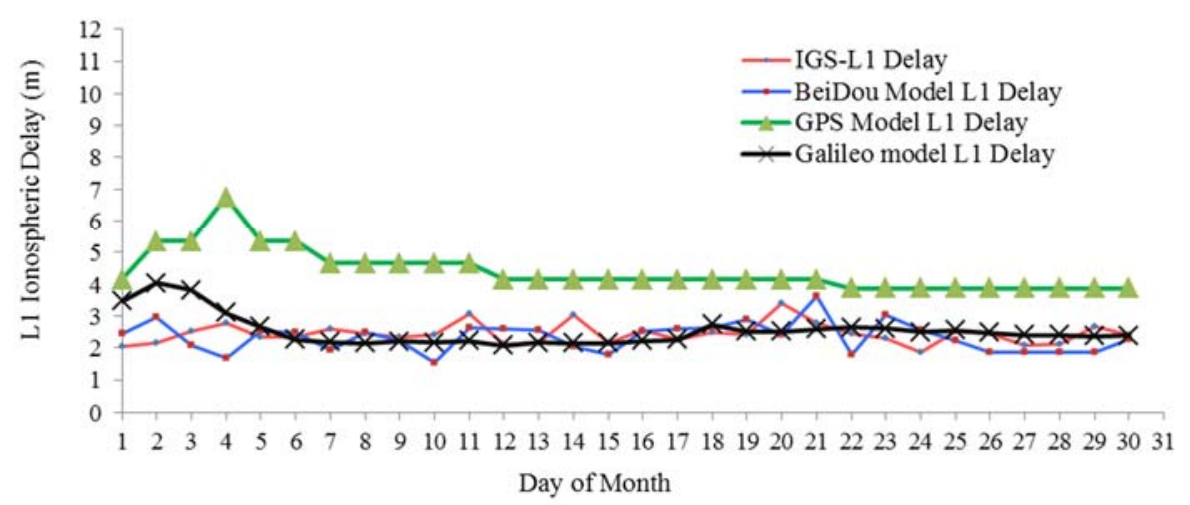

Figure 8. L1 ionospheric delay using the GPS model, BeiDou model, Galileo model, and IGS-GIMs for Sofia station during April 2017.

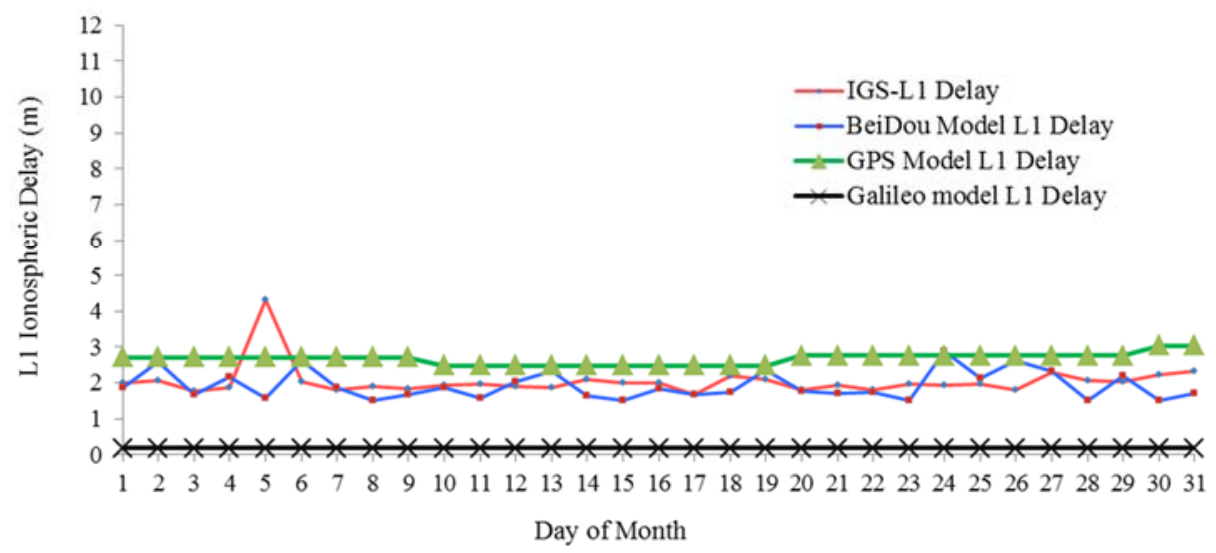

Figure 9. L1 ionosphere delay using the GPS model, BeiDou model, Galileo model, and IGS-GIMs for Sofia station during August 2019.

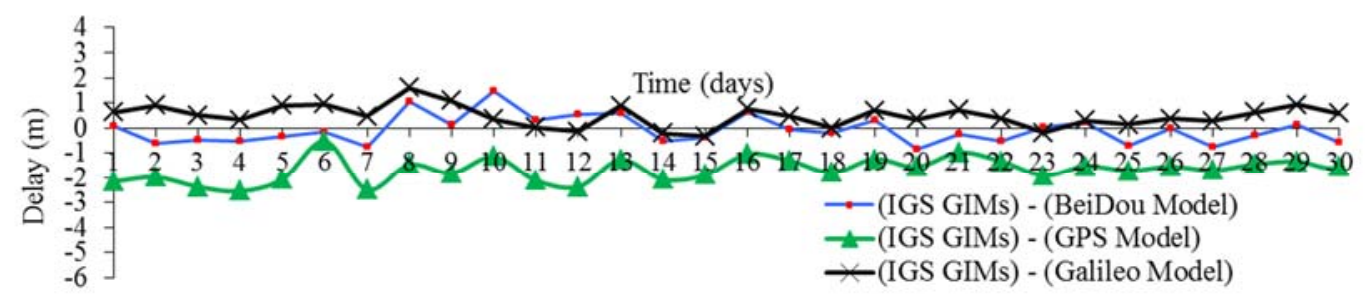

Figure 10. L1 range delay difference for Sofia station during May 2016. 


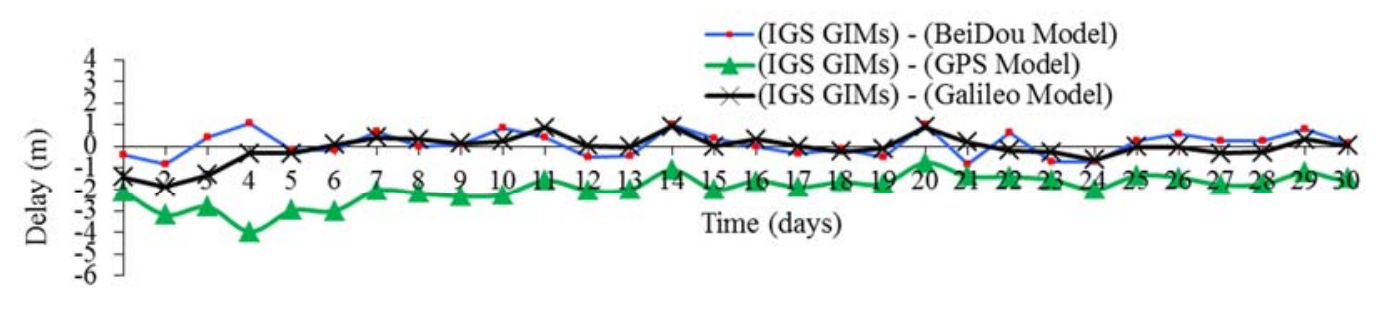

Figure 11. L1 range delay difference for Sofia station during April 2017.

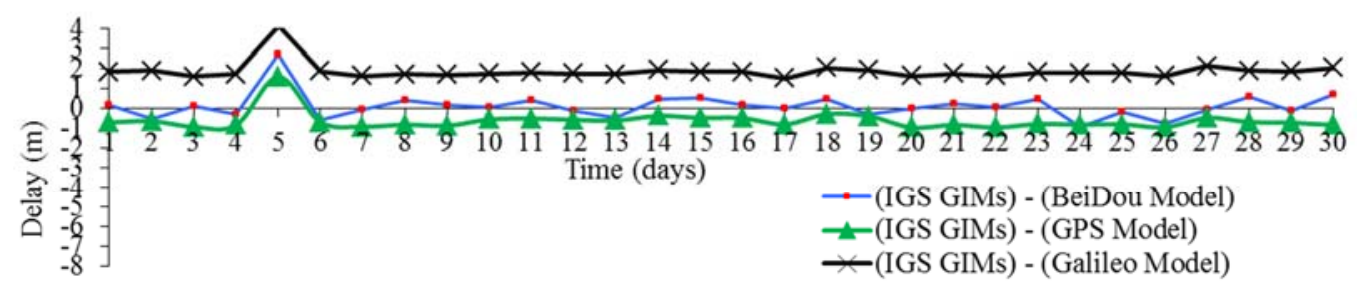

Figure 12. L1 range delay difference for Sofia station during August 2019.

\subsection{High-latitude geographic region}

The zenith ionospheric delay estimations presented by GPS, BeiDou, and Galileo models with the IGS-GIMs are presented in Figures 13-15 for high-latitude station (Helsinki). The zenith ionospheric delay differences for the three models with respect to the IGS-GIMs are presented in Figures 16-18.

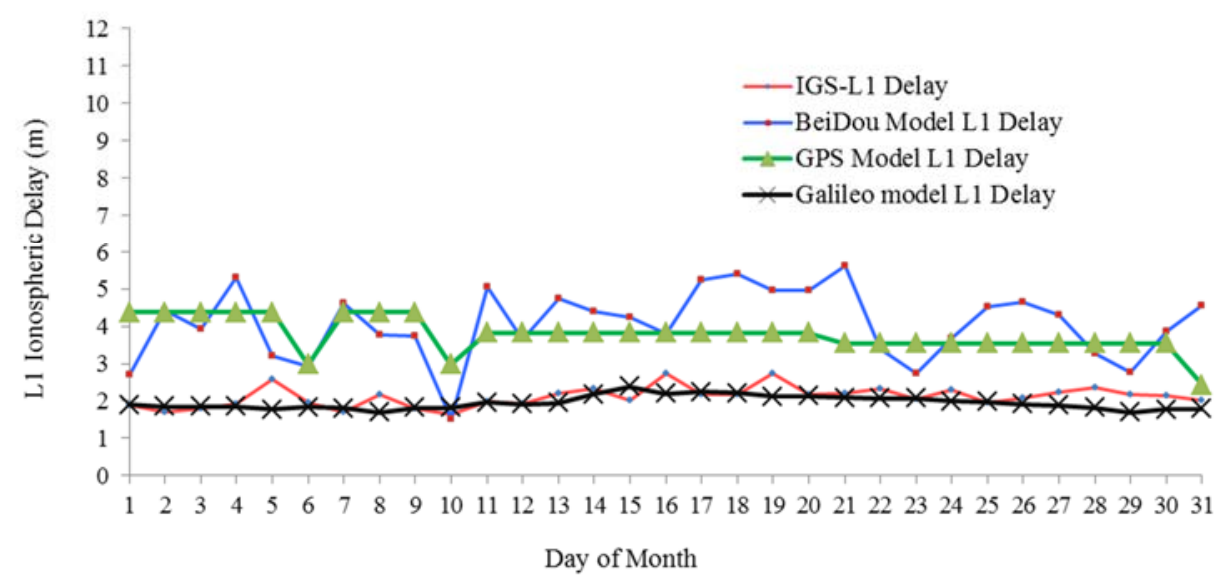

Figure 13. L1 ionospheric delay using the GPS model, BeiDou model, Galileo model and IGS-GIMs for Helsinki station during May 2016. 


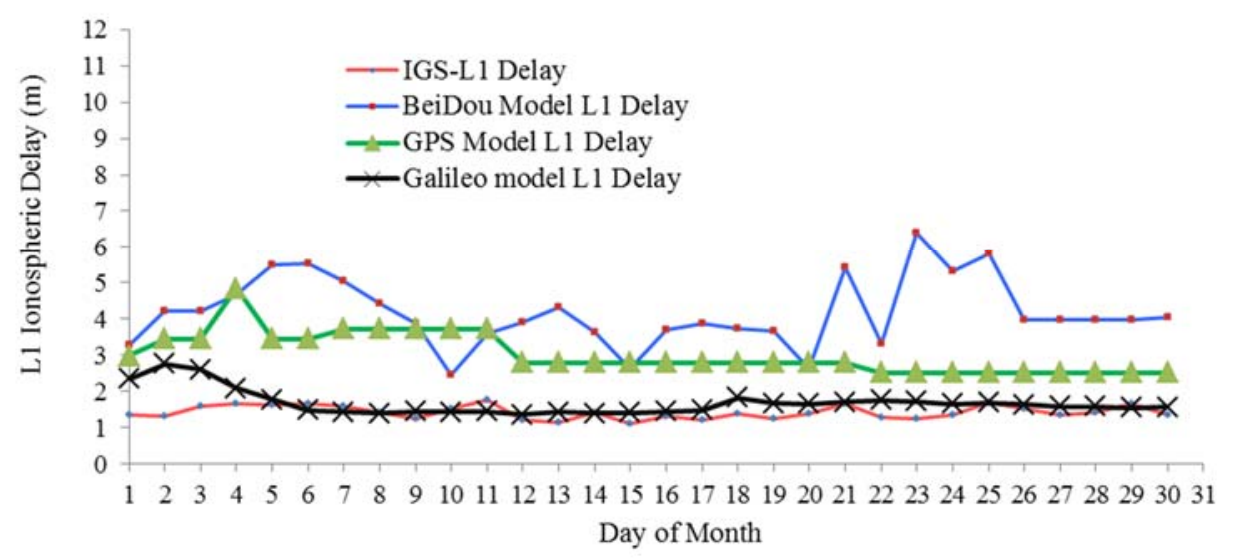

Figure 14. L1 ionospheric delay using the GPS model, BeiDou model, Galileo model, and IGS-GIMs for Helsinki station during April 2017.

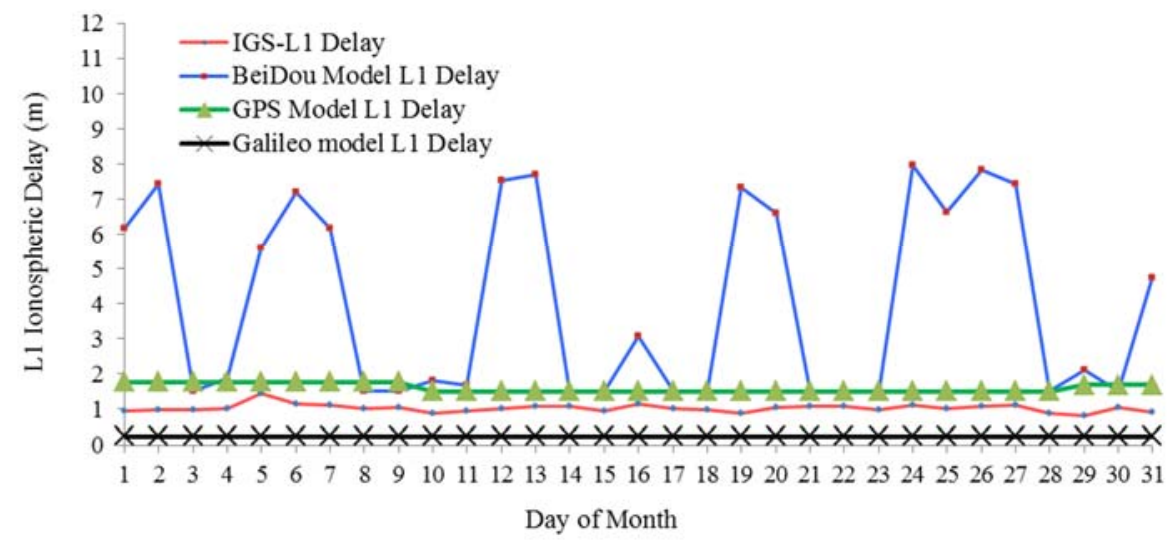

Figure 15. L1 ionospheric delay using the GPS model, BeiDou model, Galileo model, and IGS-GIMs for Helsinki station during August 2019.

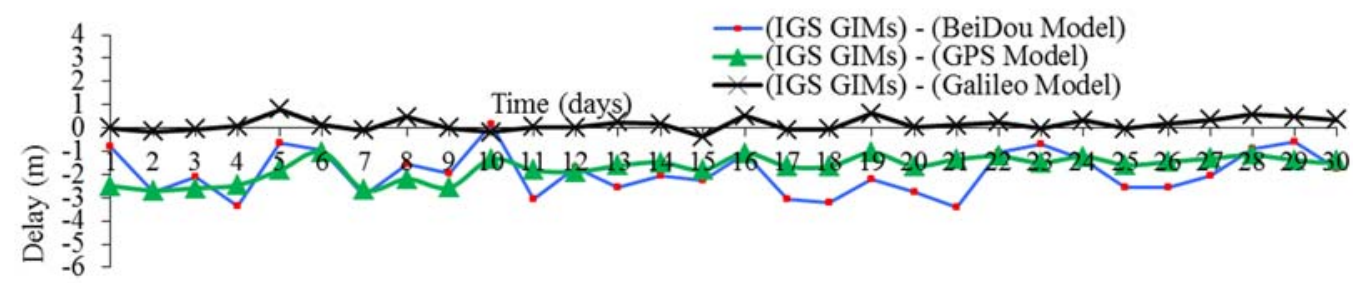

Figure 16. L1 range delay difference for Helsinki station during May 2016. 


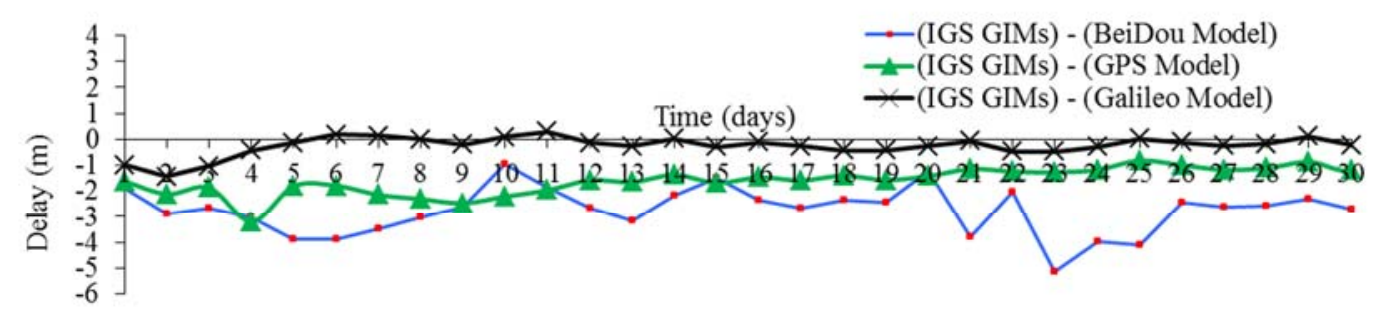

Figure 17. L1 range delay difference for Helsinki station during April 2017.

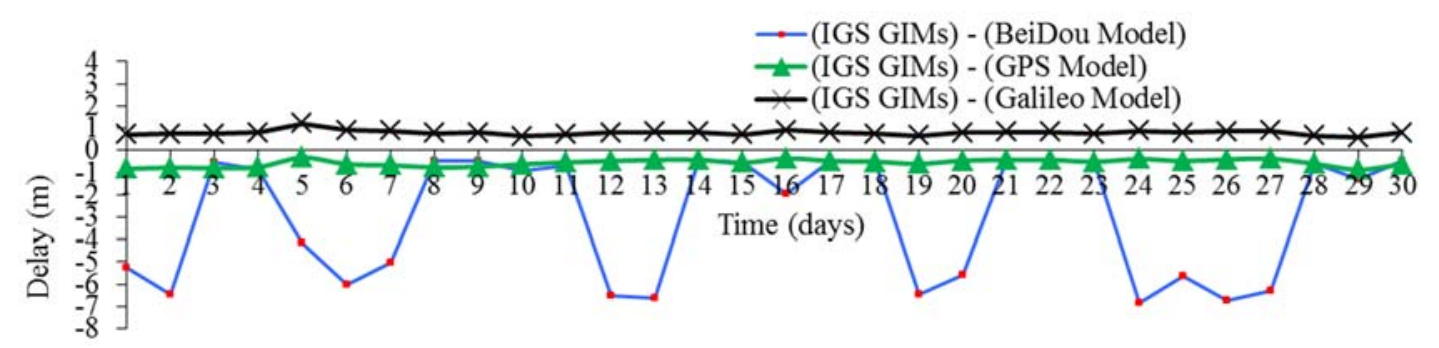

Figure 18. L1 range delay difference for Helsinki station during August 2019.

Tables 3-5 offer the statistical analysis of the L1 range delay differences from tested models with respect to IGS-GIMs for the different geographical regions (stations) and the different tested months.

Table 3. Statistical analysis for L1 zenith ionospheric delay difference (in meters) from GPS model, BeiDou model, and Galileo model with respect to IGS-GIMs for Aswan station (lower latitude).

\begin{tabular}{|l|c|c|c|c|c|c|c|c|c|}
\hline & \multicolumn{3}{|l}{$\begin{array}{l}\text { Low Ionospheric Activity } \\
\text { (August 2019) }\end{array}$} & \multicolumn{2}{l|}{$\begin{array}{l}\text { Medium Ionospheric Activity } \\
\text { (April 2017) }\end{array}$} & \multicolumn{3}{l|}{$\begin{array}{l}\text { High Ionospheric Activity } \\
\text { (May 2016) }\end{array}$} \\
& $\begin{array}{c}\text { GPS } \\
\text { Model }\end{array}$ & $\begin{array}{c}\text { BeiDou } \\
\text { Model }\end{array}$ & $\begin{array}{c}\text { Galileo } \\
\text { Model }\end{array}$ & $\begin{array}{c}\text { GPS } \\
\text { Model }\end{array}$ & $\begin{array}{c}\text { BeiDou } \\
\text { Model }\end{array}$ & $\begin{array}{c}\text { Galileo } \\
\text { Model }\end{array}$ & $\begin{array}{c}\text { GPS } \\
\text { Model }\end{array}$ & $\begin{array}{c}\text { BeiDou } \\
\text { Model }\end{array}$ & $\begin{array}{c}\text { Galileo } \\
\text { Model }\end{array}$ \\
\hline Average & -0.395 & -0.366 & 1.747 & -0.919 & -2.331 & -3.350 & 0.782 & -1.214 & -0.755 \\
\hline Maximum & 1.081 & 1.166 & 3.109 & 0.475 & -0.775 & -1.534 & 3.777 & -0.079 & 1.708 \\
\hline Minimum & -0.953 & -1.172 & 1.307 & -3.391 & -3.879 & -5.664 & -0.602 & -2.609 & -2.134 \\
\hline Root mean square & 0.392 & 0.500 & 0.389 & 0.863 & 0.848 & 0.789 & 0.899 & 0.643 & 0.908 \\
\hline
\end{tabular}


Table 4. Statistical analysis for L1 zenith ionospheric delay difference (in meters) from GPS model, BeiDou model, and Galileo model with respect to IGS-GIMs for Sofia station (mid latitude).

\begin{tabular}{|l|c|c|c|c|c|c|c|c|c|}
\hline & \multicolumn{3}{|l|}{$\begin{array}{l}\text { Low Ionospheric Activity } \\
\text { (August 2019) }\end{array}$} & \multicolumn{3}{l|}{$\begin{array}{l}\text { Medium Ionospheric Activity } \\
\text { (April 2017) }\end{array}$} & \multicolumn{3}{l|}{$\begin{array}{l}\text { High Ionospheric Activity } \\
\text { (May 2016) }\end{array}$} \\
\hline & $\begin{array}{c}\text { GPS } \\
\text { Model }\end{array}$ & $\begin{array}{c}\text { BeiDou } \\
\text { Model }\end{array}$ & $\begin{array}{c}\text { Galileo } \\
\text { Model }\end{array}$ & $\begin{array}{c}\text { GPS } \\
\text { Model }\end{array}$ & $\begin{array}{c}\text { BeiDou } \\
\text { Model }\end{array}$ & $\begin{array}{c}\text { Galileo } \\
\text { Model }\end{array}$ & $\begin{array}{c}\text { GPS } \\
\text { Model }\end{array}$ & $\begin{array}{c}\text { BeiDou } \\
\text { Model }\end{array}$ & $\begin{array}{c}\text { Galileo } \\
\text { Model }\end{array}$ \\
\hline Average & -0.624 & 0.129 & 1.884 & -1.953 & 0.110 & -0.087 & -1.628 & -0.092 & 0.495 \\
\hline Maximum & 1.586 & 2.728 & 4.132 & -0.756 & 1.087 & 0.908 & -0.157 & 1.472 & 1.619 \\
\hline Minimum & -0.960 & -0.932 & 1.518 & -3.969 & -0.835 & -1.880 & -2.546 & -0.846 & -0.333 \\
\hline Root mean square & 0.450 & 0.634 & 0.444 & 0.689 & 0.572 & 0.613 & 0.544 & 0.557 & 0.436 \\
\hline
\end{tabular}

Table 5. Statistical analysis for L1 zenith ionospheric delay difference (in meters) from GPS model, BeiDou model, and Galileo model with respect to IGS-GIMs for Helsinki station (high latitude).

\begin{tabular}{|l|l|l|c|c|c|c|c|c|c|}
\hline & \multicolumn{2}{l}{$\begin{array}{l}\text { Low Ionospheric activity } \\
\text { (August 2019) }\end{array}$} & \multicolumn{2}{l|}{$\begin{array}{l}\text { Medium Ionospheric activity } \\
\text { (April 2017) }\end{array}$} & \multicolumn{3}{l|}{$\begin{array}{l}\text { High Ionospheric Activity } \\
\text { (May 2016) }\end{array}$} \\
\hline & $\begin{array}{c}\text { GPS } \\
\text { Model }\end{array}$ & $\begin{array}{c}\text { BeiDou } \\
\text { Model }\end{array}$ & $\begin{array}{c}\text { Galileo } \\
\text { Model }\end{array}$ & $\begin{array}{c}\text { GPS } \\
\text { Model }\end{array}$ & $\begin{array}{c}\text { BeiDou } \\
\text { Model }\end{array}$ & $\begin{array}{c}\text { Galileo } \\
\text { Model }\end{array}$ & $\begin{array}{c}\text { GPS } \\
\text { Model }\end{array}$ & $\begin{array}{c}\text { BeiDou } \\
\text { Model }\end{array}$ & $\begin{array}{c}\text { Galileo } \\
\text { Model }\end{array}$ \\
\hline Average & -0.570 & -3.001 & 0.792 & -1.604 & -2.746 & -0.251 & -1.664 & -1.950 & 0.156 \\
\hline Maximum & -0.328 & -0.428 & 1.209 & -0.816 & -0.945 & 0.305 & -0.394 & 0.140 & 0.789 \\
\hline Minimum & -0.875 & -6.849 & 0.576 & -3.185 & -5.144 & -1.429 & -2.686 & -3.429 & -0.375 \\
\hline Root mean square & 0.157 & 2.688 & 0.112 & 0.521 & 0.906 & 0.369 & 0.559 & 0.952 & 0.267 \\
\hline
\end{tabular}

\section{DISCUSSION}

This study aims to present the behavior of the three broadcast ionospheric models adopted by the three systems (GPS, BeiDou [BDS-2], and Galileo) in estimating zenith ionospheric delay. The study takes into account the variation of ionospheric delay over geographic regions at different latitudes as well as its variation with solar activity states. The study covers 3 months of different ionospheric activity states (Table 2) for three stations at different latitudes (Table 1). The behavior of the three tested models is evaluated by comparing with the most accurate IGS-GIMs.

For low-latitude regions such as Aswan station, it can be concluded from the findings of this study that Galileo model is performing better than the GPS and BeiDou models in estimating the zenith ionospheric delay during high ionospheric activity state, whereas the GPS and BeiDou models are performing better than Galileo model during low and medium ionospheric activity states. Both the Galileo and BeiDou models are capable to show day-to-day significant fluctuations in the ionosphere layer behavior because of their daily updated coefficients, whereas the GPS model is not able to do so because its coefficients are not updated on a daily basis. The GPS model is sending the same coefficients for many successive days. The Galileo model is overestimating the zenith ionospheric delay during the medium-activity ionosphere, whereas the same model is underestimating the zenith ionospheric delay during the low-activity ionosphere. The GPS model is performing better than the BeiDou model during states of medium and high-activity ionosphere, whereas both models are presenting similar behavior during the state of low-activity ionosphere. It can be advised to use the BeiDou model or the GPS model for estimating the zenith ionospheric delay for low-latitude stations during the state of the low-activity ionosphere with a correction accuracy of more than $100 \%$ over the Galileo model. Also, for low-latitude stations during the state of the medium-activity ionosphere, it is advised to use the GPS model for estimating the zenith ionospheric delay with a correction accuracy of more than $100 \%$ over the Galileo and BeiDou models. For low-latitude stations during the state of high-activity ionosphere, it is advised to use the Galileo model for estimating the zenith ionospheric delay with a correction accuracy of more than $60 \%$ over the BeiDou model. 
For mid-latitude geographic region such as Sofia station, it can be concluded that the BeiDou model is performing the best in estimating the zenith ionospheric delay for different ionospheric activity states compared with the GPS and Galileo models. The BeiDou model can accurately estimate the ionospheric delay during low and high ionospheric activity states with a correction accuracy of more than $100 \%$ over the GPS and BeiDou models. For medium ionospheric activity state, both the BeiDou and Galileo models present similar behavior and can be used for the ionospheric delay estimation with a correction accuracy of more than $100 \%$ over the GPS model.

For high-latitude regions such as Helsinki station, the Galileo model presents the best performance over the other two models during medium and high ionospheric activity states with a correction accuracy of more than $100 \%$ over the GPS and BeiDou models. For low ionospheric activity state, the GPS and Galileo models perform better than the BeiDou model with a correction accuracy of more than $100 \%$.

\section{CONCLUSIONS}

Single-frequency GNSS users can correct their observations from largest source of error, which is the ionospheric delay, using a model from three broadcast models; GPS, BeiDou (BDS-2), and Galileo models. The models' coefficients are sent through navigation message of the used system.

Users from low-latitude regions are advised to use the GPS model or the BeiDou model to correct for the ionospheric delay during the state of low-activity ionosphere. Users from lowlatitude regions during the state of medium-activity ionosphere are advised to use the GPS model. Users from low-latitude regions during the state of high-activity ionosphere are advised to use the Galileo model.

Users from mid-latitude regions are advised to use the BeiDou model to correct for the ionospheric delay during the different states of ionospheric activity. Users from mid-latitude regions are advised to use the BeiDou model or the Galileo model during the state of mediumactivity ionosphere.

Users from high-latitude regions are advised to use Galileo model to correct for the ionospheric delay during the state of low- or high-activity ionosphere. Users from highlatitude regions are advised to use the GPS model or Galileo model during the state of medium-activity ionosphere.

The BeiDou model and Galileo model are able to model the ionosphere's day-to-day fluctuations because of its dependence on daily updated coefficients whereas the GPS model is unable to show those fluctuations because its ionospheric coefficients are not updated on a daily basis.

\section{REFERENCES}

Bilitza, D. (2001). International Reference Ionosphere 2000. Journal of Radio Science, Vol. 36, No. 2, pp. 261-275.

Di Giovanni, G., Radicella, S., 1990. An analytical model of the electron density profile in the ionosphere. Adv. Space Res. 10 (11), 27-30.

European Commission (2016) .European GNSS (Galileo) Open Service Ionospheric Correction Algorithm for Galileo Single Frequency Users., Issue 1.2, Sep., 2016, pp. 4-29.

https://www.gsc-europa.eu/sites/default/files/sites/all/files/Galileo_Ionospheric_Model.pdf 
Hernández-Pajares M., Juan J.M., Sanz J., Aragón-Àngel À., García-Rigo A., Salazar D., Escudero M. (2011). The ionosphere: effects, GPS modeling and the benefits for space geodetic techniques. J. Geod. 85 (12): 887-907.

Hofmann-Wellenhof B., Lichtenegger H., Wasle E. (2008). GNSS-global navigation satellite systems - GPS, GLONASS, Galileo, and more. Springer, Vienna. doi:10.1007/9783-211-73017-1.

IGS (2019a). The ionospheric coefficients for GPS, BeiDou and Galileo ionospheric models. (ftp://cddis.gsfc.nasa.gov/pub/gps/data/daily/2017/010/17p/) (Accessed 1/9/2019).

IGS (2019b). IGS-GIMs (International GNSS Service-Global Ionospheric Maps (IONEX format)) (ftp://cddis.gsfc.nasa.gov/gps/products/ionex/) (Accessed 1/9/2018).

Klobuchar, J. A. (1987). Ionospheric Time-Delay Algorithm for Single-Frequency GPS Users. IEEE Transactions on Aerospace and Electronic Systems. Vol. AES-23, No. 3, pp. 325-331.

Kunches, J. M. and Klobuchar, J. A. (2001). Eye on The Ionosphere: GPS after SA. GPS Solutions 4(3), PP. 52-54.

Nava, B., Coïsson, P., Radicella, S.M., (2008). A new version of the NeQuick ionosphere electron density model. J. Atmos. Sol. Terr. Phys. 70 (15), 1856-1862.

Newby, S.P. and R.B. Langley (1992). Three alternative empirical ionospheric models --Are they better than the GPS Broadcast Model. Proceedings of the 6th International GeodeticSymposium on Satellite Positioning, Columbus, OH, 17-20 March, pp. 240-244.

Ningbo Wang, Zishen Li, Min Li, Yunbin Yuan, Xingliang Huo (2018). GPS, BDS and Galileo ionospheric correction models: An evaluation in range delay and position domain. Journal of Atmospheric and Solar-Terrestrial Physics (170) (2018) 83-91.

Prasad N, Sarma AD (2004). Ionospheric time delay estimation using IDW grid model for GAGAN. J Indian Geophys Union 8(4):319-327.

Prieto-Cerdeira, R., Orús-P_erez, R., Breeuwer, E., Lucas-Rodriguez, R., Falcone, M. (2014). Performance of the Galileo single-frequency ionospheric correction during in-orbit validation. GPS World 25 (6), 53-58.

Rovira-Garcia A., Juan J., Sanz J., González-Casado G., Ibáñez D., (2016). Accuracy of ionospheric models used in GNSS and SBAS: methodology and analysis. J. Geod. 90 (3): $229-240$

Sharma S, Galav P (2011). Longitudinal study of the ionospheric response to the geomagnetic storm of 15 May 2005 and manifestation of TADs. Ann Geophys 29:1063-1070.

SIDC (2019). Monthly mean total sunspot number $[1 / 1749$ - now $]$. (http://www.sidc.be/silso/datafiles). Accessed (1/9/2019).

Wang N, Li Z, Min L, Yuan Y, Huo X. (2018). GPS, BDS and Galileo ionospheric correction models: An evaluation in range delay and position domain. Journal of Atmospheric and SolarTerrestrial Physics: S291327682. Volume 170, p. 83-91. 
Wu, X., Hu, X., Wang, G., et al. (2013). Evaluation of COMPASS ionospheric model in GNSS positioning. Adv. Space Res. 51 (6): 959-968.

Zhao Wenjun, Qing Gao and Daliang Gong (2014). Analysis on Correction Accuracy of Ionospheric Model for BeiDou System. China Satellite Navigation Conference (CSNC). Proceedings: Volume I, Lecture Notes in Electrical Engineering 303, Springer.

Received: 2020-01-30

Reviewed: $\quad 2020-03-29$ and 2020-04-07

Accepted: 2020-04-16 